\title{
Water Quality in Marginal Seas off China in the Last Two Decades
}

\author{
Baodong Wang, Linping Xie, and Xia Sun \\ The First Institute of Oceanography, State Oceanic Administration, Qingdao 266061, China \\ Correspondence should be addressed to Baodong Wang, wangbd@fio.org.cn
}

Received 25 October 2010; Revised 20 January 2011; Accepted 11 March 2011

Academic Editor: Robert Frouin

Copyright () 2011 Baodong Wang et al. This is an open access article distributed under the Creative Commons Attribution License, which permits unrestricted use, distribution, and reproduction in any medium, provided the original work is properly cited.

\begin{abstract}
Based on historical data, variations in seawater quality and pollutant origins in marginal seas off China in the recent two decades are overviewed. Analysis shows that the total area of nonclean water was increasing continuously in the 1990s, but it has been decreasing since 2000; however, the total polluted area (sum of areas of slightly, medium, and heavily polluted waters) in China's standard fluctuated without a clear trend of decline or increase, indicating that although the increasing trend of marine environmental pollution has been kept effectively within certain limits, seawater quality has not been improved essentially in marginal seas off China. Furthermore, the occurrence frequency and affected area of HABs increased rapidly in marginal seas off China in the last 20 years. The amount of industrial and municipal discharges from the mainland China increased from the end of the 1980s to the end of the 1990s but decreased in the 2010s whereas riverine input of nutrients and pollutants from marine sources increased continuously.
\end{abstract}

\section{Introduction}

Good environmental quality is essential for sustaining coastal and marine ecosystems, commercial and recreational fisheries, and economic growth in coastal regions [1]. The health of coastal and marine ecosystems is affected by seawater quality, which in turn is dependent upon ecosystem health.

In the past three decades, China has experienced rapid industrialization and economic growth. The living standard of Chinese people has been considerably enhanced; however, environmental degradation has also become an obvious problem [2]. Agricultural and industrial discharges as well as municipal sewage have resulted in damages to the coastal ecosystems off China [2].

The marginal seas off China are parts of the western North Pacific, including the Bohai Sea (BS), the Yellow Sea (YS), the East China Sea (ECS), and the South China Sea (SCS) (Figure 1). China has $1.8 \times 10^{4} \mathrm{~km}$ of continental coastline and $3.0 \times 10^{6} \mathrm{~km}^{2}$ of "blue territory." Total river discharge from mainland China is $1300 \times 10^{9} \mathrm{~m}^{3} / \mathrm{a}$ [4], including some of the largest rivers in the world, namely, the Changjiang (Yangtze) River, the Huang he (Yellow) River, and the Zhu jiang (Pearl) River, which bring anthropogenic materials from catchments into the sea. In addition to all continental sources, China's coastal ecosystems also suffer from extensive human activities such as coastal engineering, shipping, mariculture, and offshore gas and oil exploitation $[5,6]$.

This paper provides a brief overview of the seawater quality and related problems in marginal seas off China in the recent two decades. The input pressures from both continental and marine sources are discussed.

\section{Materials and Methods}

Data for seawater quality status assessment were collected from the Marine Environment Quality Communiqué of China (1989-2009) published by State Oceanic Administration (SOA) of China [3]. These communiqués were based on data of routine monitoring in hundreds of fixed stations in marginal seas off China. Data on harmful algal blooms (HABs) incidents were from Marine Disaster Communiqué of China (1989-2009) published by SOA [7]. Data for pollutant origins were from published communiqués by SOA [3] and State Environment Protection Agency [8] and other published data which were based on routine monitoring.

Classification of seawater quality levels was in accordance with the Sea Water Quality Standard of China [9], and the 
classification standards for clean water, relatively clean water, slightly polluted water, medium polluted water, and heavily polluted water were listed in Table 1 . In this paper, first, the seawater was divided into clean water and nonclean water; second, the nonclean water was divided into relatively clean water and (total) polluted water; third, the (total) polluted water was divided into slightly polluted water, medium polluted water, and heavily polluted water. Therefore, the total area of nonclean water was the sum of areas of relatively clean water and (total) polluted water; the total polluted area was the sum of areas of slightly polluted water, medium polluted water, and heavily polluted water.

Seawater quality level for a given sea area was classified according to National Seawater Quality Standards using "one out, all out" principal, that is, seawater quality level was determined by the variable which fell into the highest category of seawater quality in Table 1. The areas with different seawater quality levels were computed using a GIS system.

\section{Results and Discussion}

3.1. Variations of Seawater Quality. Variation of the total area of nonclean water in marginal seas off China could be divided into two stages with the year 2000 as a turning point (Figure 2). In the 1990s, the total area of nonclean water increased linearly from $1.0 \times 10^{5} \mathrm{~km}^{2}$ in 1992 to $2.06 \times$ $10^{5} \mathrm{~km}^{2}$ in 2000 . However, although it fluctuated, a declining trend was observed after 2000. Compared with that in 2000, the total area of nonclean water in the recent five-year (20052009) was reduced by one-third and maintained at a nearly constant level (Figure 2).

The trend in variation of area of relatively clean waters was similar to that of the total area of nonclean water, and area of relatively clean waters at present is about half of that in the end of the 1990s and the beginning of 21 century (Figure 2). However, variations in areas of other seawater quality levels were quite different. Areas of slightly, medium, and heavily polluted waters fluctuated without clear trends of decline or increase, and they accounted for $22 \%, 12 \%$, and $18 \%$ of the total area of nonclean water, respectively (Figure 2). Total polluted sea area also fluctuated without a clear trend of decline or increase, indicating that seawater quality has not been improved essentially in China seas.

Variations in areas with different seawater quality levels in the BS, YS, ECS, and SCS were different, to some extent, to those of total China seas. In the BS, the total area of nonclean water decreased in the last decade, so did the relatively clean water; however, all the areas of slightly, medium, and heavily polluted waters increased in the last decades (Figure 3(a); $[15,16])$. In another word, although the total area of nonclean water declined, the level of pollution in coastal water has worsened in BS in the last decade. In the YS, the area of relatively clean water decreased by $60 \%$ from the beginning to the end of the 2010s whereas the variations in areas of other seawater quality levels demonstrated saddlelike trends in the last decade, with peaks in the middle of the 2010s (Figure 3(b)). In the ECS, all the areas with

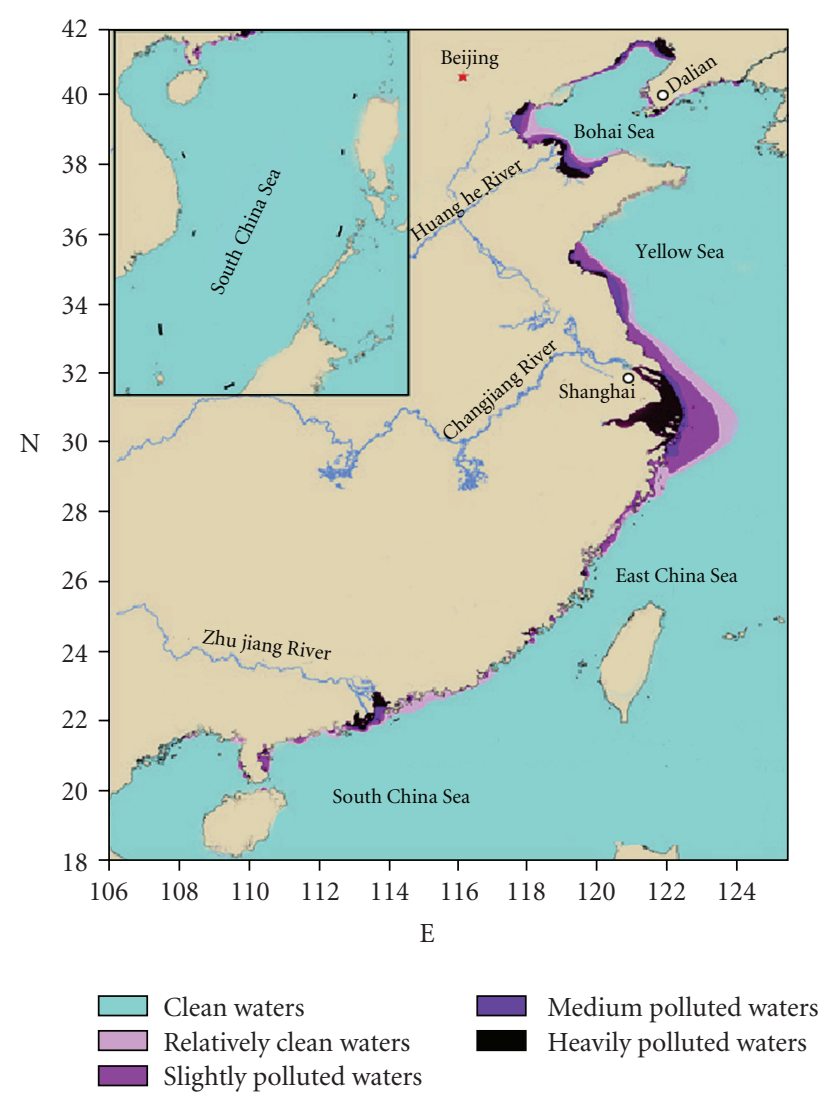

FIGURE 1: Map of China seas and seawater quality in 2007 (data source: [3]).

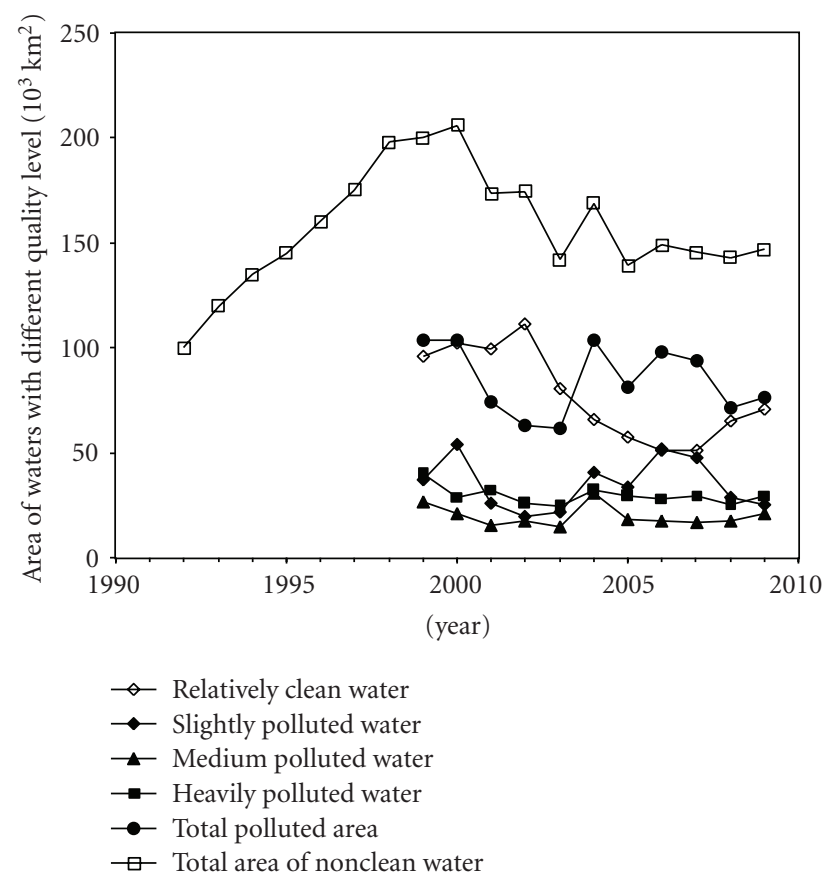

FIGURE 2: Variation of seawater quality in marginal seas off China in the recent two decades (data source: [3]). 
TABLE 1: Seawater Quality Standard of China (GB3097-1997, excerpt; unit: mg L ${ }^{-1}$ ).

\begin{tabular}{|c|c|c|c|c|c|}
\hline Item & $\begin{array}{l}\text { Clean water } \\
\text { (Category I) }\end{array}$ & $\begin{array}{c}\text { Relatively } \\
\text { clean water } \\
\text { (Category II) }\end{array}$ & $\begin{array}{c}\text { Slightly polluted } \\
\text { water } \\
\text { (Category III) } \\
\end{array}$ & $\begin{array}{c}\text { Medium } \\
\text { polluted water } \\
\text { (Category IV) }\end{array}$ & $\begin{array}{l}\text { Heavily polluted } \\
\text { water (inferior } \\
\text { to Category IV) }\end{array}$ \\
\hline Dissolved oxygen & $>6$ & $>5$ & $>4$ & $>3$ & $<3$ \\
\hline Chemical oxygen demand (COD) & $\leq 2$ & $\leq 3$ & $\leq 4$ & $\leq 5$ & $\geq 5$ \\
\hline Biochemical oxygen demand $\left(\mathrm{BOD}_{5}\right)$ & $\leq 1$ & $\leq 3$ & $\leq 4$ & $\leq 5$ & $\geq 5$ \\
\hline Inorganic nitrogen (as $\mathrm{N}$ ) & $\leq 0.20$ & $\leq 0.30$ & $\leq 0.40$ & $\leq 0.50$ & $\geq 0.50$ \\
\hline Phosphate (as P) & $\leq 0.015$ & $\leq 0.030$ & \multicolumn{2}{|c|}{$\leq 0.045$} & $\geq 0.045$ \\
\hline Mercury & $\leq 0.00005$ & $\leq 0.0002$ & \multicolumn{2}{|c|}{$\leq 0.0005$} & $\geq 0.0005$ \\
\hline Cadmium & $\leq 0.001$ & $\leq 0.005$ & \multicolumn{2}{|c|}{$\leq 0.010$} & $\geq 0.010$ \\
\hline Lead & $\leq 0.001$ & $\leq 0.005$ & $\leq 0.010$ & $\leq 0.050$ & $\geq 0.050$ \\
\hline Chromium (VI) & $\leq 0.005$ & $\leq 0.010$ & $\leq 0.020$ & $\leq 0.050$ & $\geq 0.050$ \\
\hline Total chromium & $\leq 0.05$ & $\leq 0.10$ & $\leq 0.20$ & $\leq 0.50$ & $\geq 0.50$ \\
\hline Arsenic & $\leq 0.020$ & $\leq 0.030$ & \multicolumn{2}{|c|}{$\leq 0.050$} & $\geq 0.050$ \\
\hline Copper & $\leq 0.005$ & $\leq 0.010$ & \multicolumn{2}{|c|}{$\leq 0.050$} & $\geq 0.050$ \\
\hline Zinc & $\leq 0.020$ & $\leq 0.050$ & $\leq 0.10$ & $\leq 0.50$ & $\geq 0.50$ \\
\hline Oil & $\leq 0.05$ & $\leq 0.30$ & \multicolumn{2}{|c|}{$\leq 0.50$} & $\geq 0.50$ \\
\hline
\end{tabular}

different seawater quality levels declined in the beginning of the 2010s, and then they maintained at nearly constant levels from the middle to the end of the 2010s (Figure 3(b)). In the SCS, variations of areas with different seawater quality levels could be divided into two stages with the year 2005 as a turning point in the last decade (Figure 3(d)). Variations in the areas with different seawater quality levels demonstrated saddle-like trends in the first half of the 2010s whereas they increased, in different extent, in the second half of the 2010s, indicating a worsening trend in the SCS in recent years.

The distribution of main polluted areas concentrated in coastal areas of the Liaodong Bay, Bohai Bay, Huang he (Yellow) River estuary, and Laizhou Bay in BS, the Yalu jiang River estuary, Dalian Bay, and coastal areas of the southern west in YS, the Changjiang River estuary and Hangzhou Bay in ECS, and the Zhu jiang River estuary in SCS (Figure 1). Main pollutants in China seas are dissolved inorganic nitrogen (DIN), dissolved inorganic phosphate (DIP), petroleum hydrocarbons (oil), and heavy metals [3, 17]. The areas with different seawater quality levels were determined by the concentration of DIP in the Liaodong Bay, and by the concentration of DIN in other areas of marginal seas off China [3].

3.2. HABs Incidents. Enrichment of nutrients have caused severe eutrophication in the extended coastal waters, and harmful algal blooms (HABs) have been frequently observed in marginal seas off China $[18,19]$. Characteristics of HAB incidents in marginal seas off China in the recent two decades are as follows. (i) A sharp increase in the number of annual $\mathrm{HAB}$ incidents. The annual HAB incidents increased from a number of less than 50 in the 1990s to 70 after 2001 and up to 119 in 2003 (see (Figure 4; [19]). The average number of annual HAB incidents after 2001 is four-times as that in the 1990s (Figure 4). (ii) A sharp increase in the annual total affected area of HAB incidents [19]. It increased from a level less than $2,000 \mathrm{~km}^{2}$ before 1997 (except 1990) to a level greater than $10,000 \mathrm{~km}^{2}$ during the period from 1998 to 2009 and reaching the highest level of $27,000 \mathrm{~km}^{2}$ in 2005 . The average annual total affected area of HABs incidents after 1998 was five-times as that before 1997 (Figure 4). (iii) An increase in the number of toxic HABs incidents. The number of annual toxic HABs incidents was more than 25 in recent years, and the affected area was about $15,000 \mathrm{~km}^{2}$ in both 2005 and 2006 [7]. The species of toxic algal blooms were mainly Karenia mikimotoi, Phaeocysti, Cochlodinium polykrikoides, and so forth [18-20]. (iv) An increase in the proportion of large-size affected areas of HABs incidents $[19,20]$.

The areas with frequent HABs occurrence were the Liaodong Bay and Bohai Bay in BS, the Changjiang River estuary and adjacent sea areas in ECS, and the Zhu jiang River estuary and adjacent sea areas in SCS $[7,18,19]$.

3.3. Variations of Pollution Pressures. Based on the fact that main polluted areas were located at medium to large river estuaries and their adjacent sea areas, it can be concluded that pollutants from land-based sources were the main source of pollutants in marginal seas off China. The variation trend of input pressure of pollutants from land-based sources was analyzed from the following two aspects: one is pollutant emission pressure of land-based sources, expressed as total amount of COD in industrial and municipal effluents in China; while the other is riverine flux of pollutants, taking the COD flux into the sea from the Huang he River as an example. Total amount of COD in industrial and municipal effluents in China increased rapidly from the end of the 1980s to the end of the 1990s [21], but maintained at a level of 14 million tons after the end of the 1990s (Figure 5). The COD flux into the Bohai Sea from the Huang he River increased sharply from the end of the 1980s to the mid 1990s but has decreased rapidly since the end of the 1990s (Figure 5). 


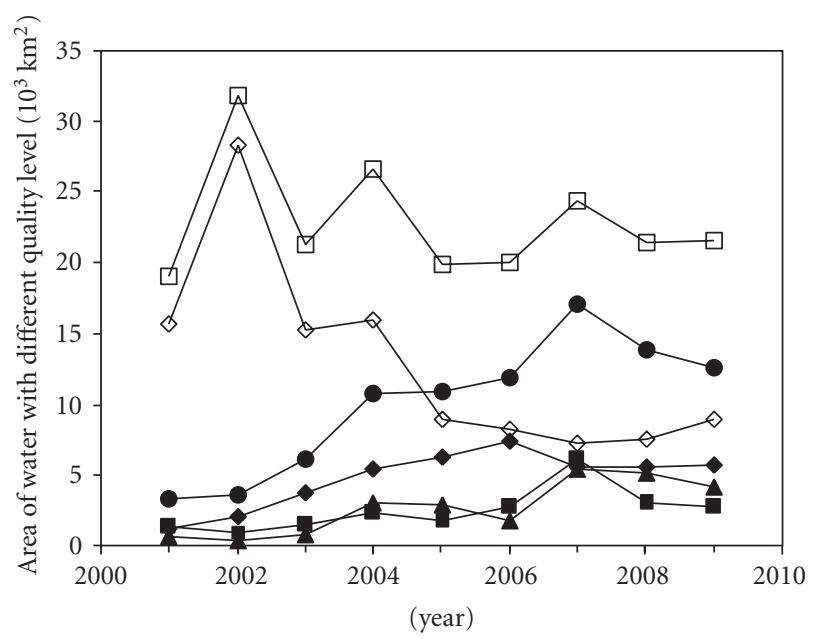

(a) The Bohai Sea

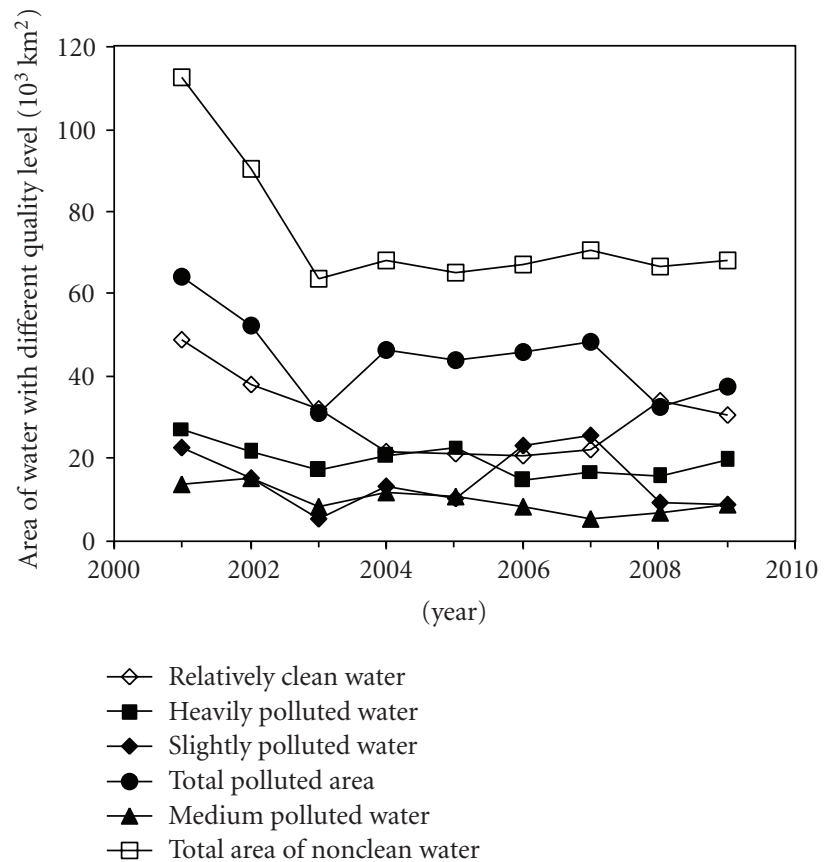

(c) The East China Sea

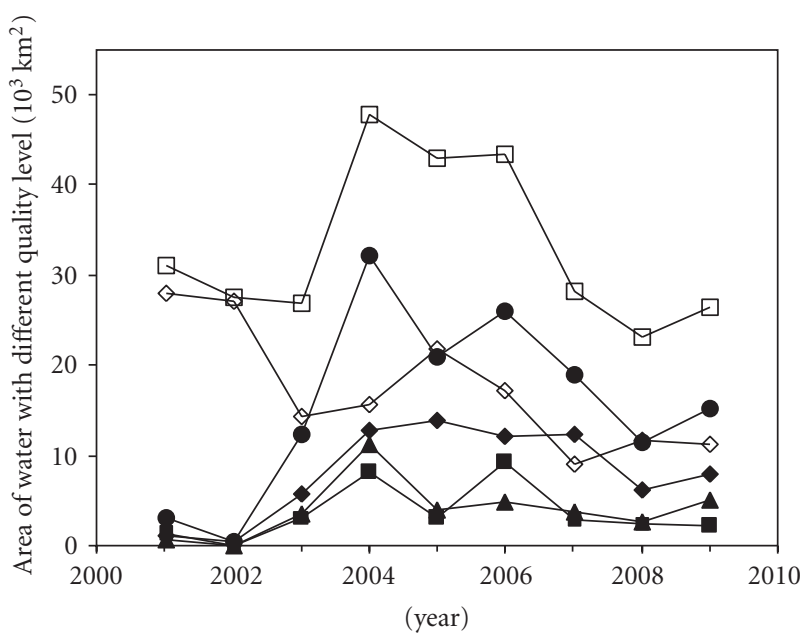

(b) The Yellow Sea

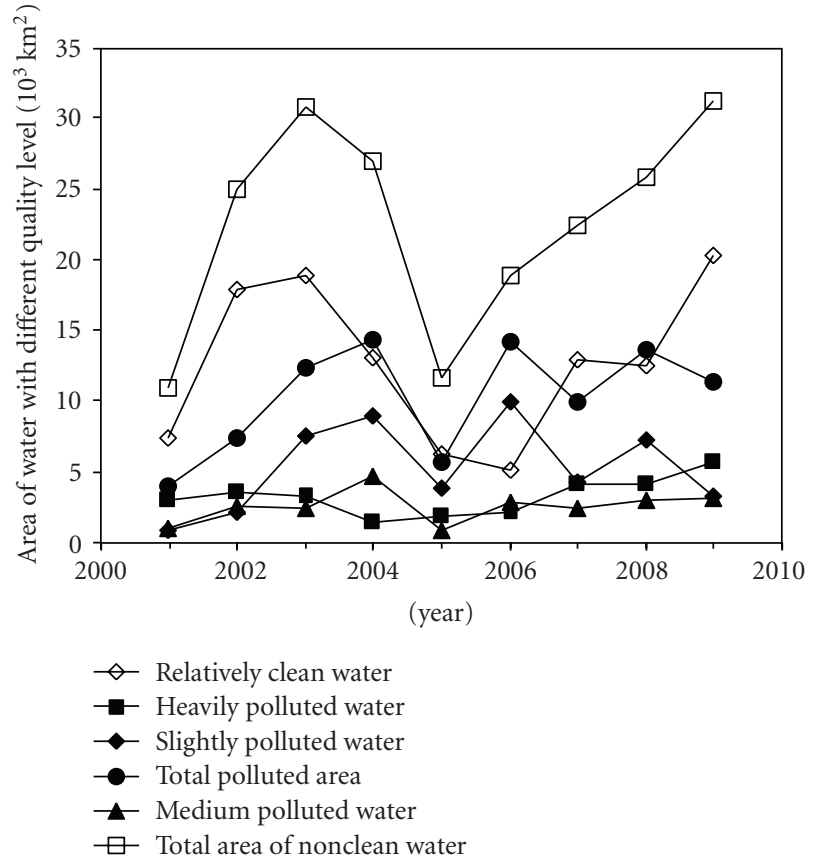

(d) The South China Sea

FIgure 3: Variations of seawater quality in the Bohai Sea, Yellow Sea, East China Sea, and South China Sea in the recent two decade (data source: [3]).

This implies that variation of riverine flux of COD reflected to some extent the changes of total amount of COD in industrial and municipal effluents in the river basin.

The pressure of pollutant emission from agriculture was expressed as the total amount of fertilizer application, and was compared with riverine flux of nutrients from the Changjiang River. Along with rapid development of agriculture in China, amount of fertilizer application increased by 1.5-times in the recent two decades [22-24]. Large amount of fertilizer was washed away into rivers through loss of water and erosion of soil and finally into the estuarine and coastal waters. This could be evidenced by sharp increase of DIN load from the Changjiang River, which is taken as a typical representative of riverine flux of nutrients from mainland China (Figure 6), indicating that pressure of nutrient input increased in marginal seas off China in recent two decades $[13,14,25]$.

Sea-based sources of pollutants are also origin of pollutants in coastal waters, such as mariculture, off-shore petroleum exploitation, and marine dumping zones. For instance, the amount of solid waste (mainly dredged material) dumping was less than $5.0 \times 10^{7} \mathrm{~m}^{3} / \mathrm{yr}$ in the $1990 \mathrm{~s}$ in marine dumping zones but has increased rapidly since 2000 and reached up to $2.0 \times 10^{8} \mathrm{~m}^{3} / \mathrm{yr}$ in 2007 , which was fourtimes higher than that in the 1990 s, but it decreased after 2007 and maintained at a level of $1.2 \times 10^{8} \mathrm{~m}^{3} / \mathrm{yr}$. Number 


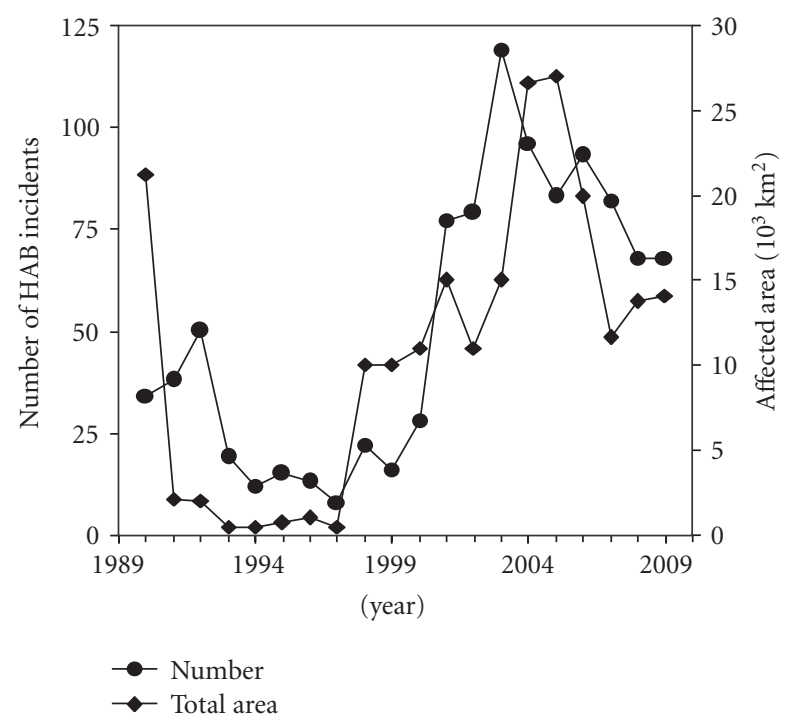

FIgURE 4: Variation of HAB incidents in marginal seas off China in the recent two decades (data source: [7]).

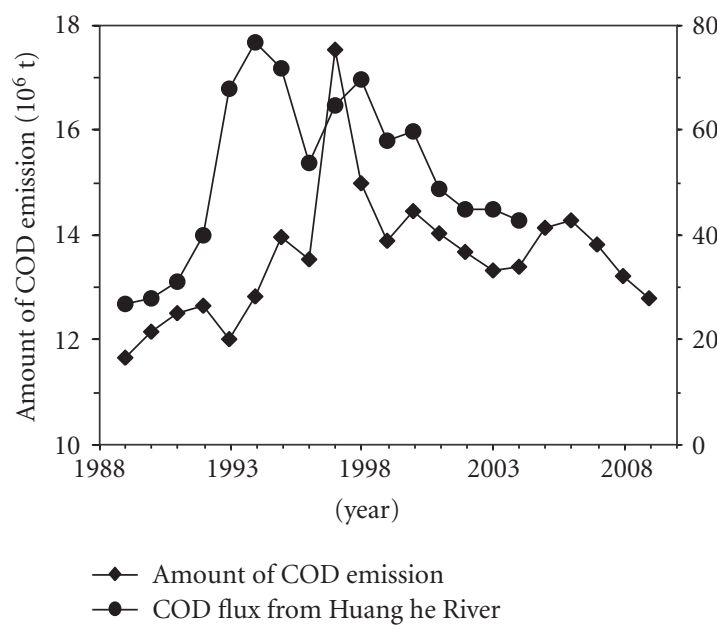

FIGURE 5: Variations of amount of COD in industrial effluents and municipal sewage in China and COD flux from the Huang he River into the sea in the recent two decades (data sources: $[8,10,11]$ ).

of oil fields in China seas also increased in recent decades [5], from nine at the beginning of the 1990s to 39 at present. Correspondingly, the amount of effluents containing oil from petroleum exploitation activities increased rapidly and was four-times higher in 2009 than that in 1999 (Figure 7). These data suggest that the pressure of sea-based sources of pollutants increased in the recent two decades, and the contributions of these pollutions to the evaluation of seawater quality in China seas have yet to be assessed further.

\section{Summary}

During the 1980s to the 1990s, pressure of pollutant input increased continuously in marginal seas off China, leading to worsening of seawater quality in coastal waters, and both the

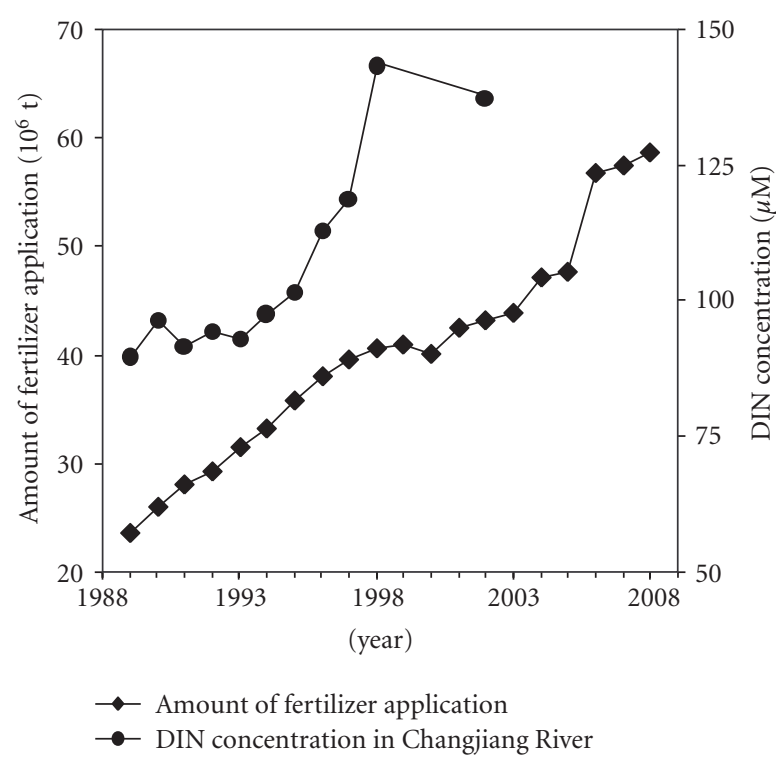

Figure 6: Variations of total amount of fertilizer application in China and DIN concentration in the Changjiang River water in the recent two decades (data sources: [12-14]).

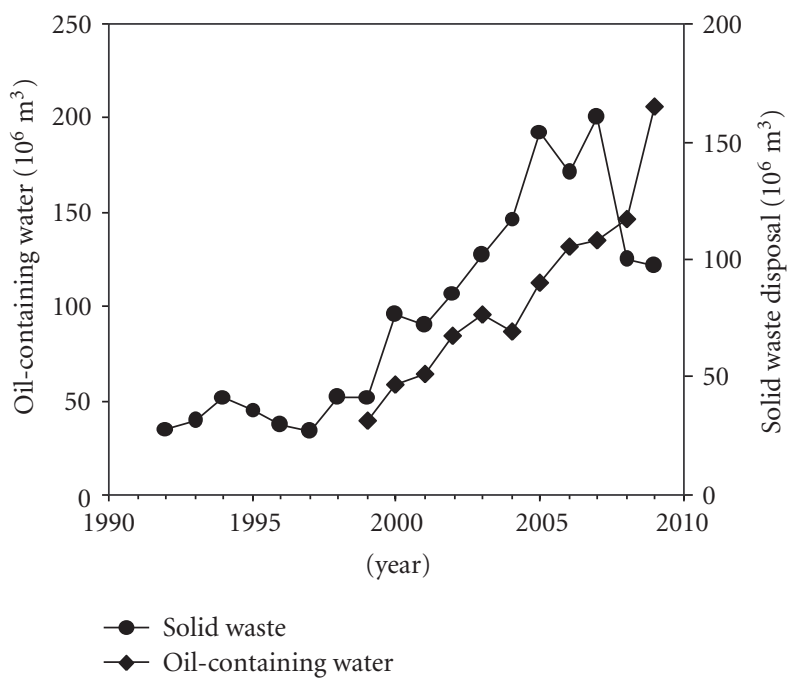

FIGURE 7: Variations of total amount of effluents containing oil from off-shore petroleum exploitation in China seas and amount of solid waste dumping (data source: [3]).

extent of pollution and affected area increased continuously. Since 2000, however, total area of nonclean water decreased, whereas the area of polluted waters fluctuated with no clear trend of decline or increase. This suggests that although the increasing trend of marine environmental pollution has been kept effectively within limits in marginal seas off China, seawater quality essentially has not improved. Clearly, variations in seawater quality were related to variations of pollutant origins from land- and sea-based sources. Variations in emissions of industrial and municipal effluents increased from the end of 1980s to the end of 1990s but decreased in the 2010s whereas the pressure of nutrient inputs as well 
as pollutants from sea-based sources increased continuously. Sharp increases in the number and total affected area of annual HAB incidents, as well as increases in the number and affected area of toxic and large-scale algal blooms, were observed in marginal seas off China in the recent two decades, indicating that coastal eutrophication worsened continuously in recent decades. Therefore, in addition to control and treatment of discharges of industrial effluents and municipal sewage, countermeasures should be taken to reduce pollutants (mainly nitrogen and phosphorus) from agriculture, such as fertilizer application with scientific methods, prevention of loss of water and erosion of soil, and construction of wet land.

\section{Acknowledgments}

This study was funded by National Key Basic Research and Development Program (973) (Grant No. 2010CB429004), Program of Investigation and Assessment of Coastal Seas of China (Contract No. 908-JC-I-03 and 908-02-09-05), and Special Program of Scientific Research for Marine Public Welfare (Grant No. 201105014-3).

\section{References}

[1] H. Vandermeulen and D. Cobb, "Marine environmental quality: a Canadian history and options for the future," Ocean and Coastal Management, vol. 47, no. 5-6, pp. 243-256, 2004.

[2] K. M. Zhang and Z. G. Wen, "Review and challenges of policies of environmental protection and sustainable development in China," Journal of Environmental Management, vol. 88, no. 4, pp. 1249-1261, 2008.

[3] SOA (State Oceanic Administration of China), "Marine Environment Quality Communiqué of China (1989-2009)," 2010, http://www.soa.gov.cn/soa/hygb/A0109index_1.htm.

[4] Z. Jianyun, W. Guoqing, Y. Yang, H. Ruimin, and L. Jiufu, "Impact of climate change on water security in China," Advances in Climate Change Research, vol. 5, supplement, pp. 34-40, 2009.

[5] X. Jin, X. You, and H. Liu, "Development of China's offshore oil resources," China Oil and Gas, vol. 3, pp. 28-32, 2008.

[6] Y. H. Li, X. P. Huang, Z. Z. Xu, and L. M. Huang, "Threat and protection measurement of Hepu seagrass beds in Guangxi," Marine Environmental Science, vol. 26, no. 6, pp. 587-589, 2007 (Chinese).

[7] SOA (State Oceanic Administration of China), "Marine Disaster Communiqué of China (1989-2009)," 2010, http://www .soa.gov.cn/soa/hygb/A0109index_1.htm.

[8] SEPA (State Environment Protection Agency of China), "Environment Status Communiqué of China (1989-2009)," 2010, http://www.mep.gov.cn/plan/zkgb.2010.8.13 .

[9] MEP (Ministry of Environmental Protection of China), Sea Water Quality Standard (GB3097-1997 replacing GB 3097-82 putting into effect as of July 1, 1998).

[10] X. Wang and K. Li, Marine Environmental Capacity of Main Pollutants in Bohai Sea, China Science Press, Beijing, China, 2006.

[11] S. Ma, F. Xin, Y. Cui, and X. Qiao, "Estimation of riverine flux of pollutants from Yellow River and Xiaoqinghe River," Marine Fishery Research, vol. 25, no. 5, pp. 47-51, 2004 (Chinese).
[12] CEIC (Chemical Engineering Information Center of China), "Statistics of fertilizer application in China (1989-2008)," 2009, http://www.sinofi.com/indexnytj.aspx.2009.9.12 .

[13] B. Wang, "Cultural eutrophication in the Yangtze River plume: history and perspective," Estuarine, Coastal and Shelf Science, vol. 69, pp. 471-477, 2006.

[14] W. J. Yan, S. Zhang, and J. H. Wang, "Nitrogen biogeochemical cycling in the Changjiang drainage basin and its effect on Changjiang river dissolved inorganic nitrogen: temporal trend for the period 1968-1997," Acta Geographica Sinica, vol. 56, no. 5, pp. 505-514, 2001.

[15] Z. Zhang, M. Zhu, Z. Wang, and J. Wang, "Monitoring and managing pollution load in Bohai Sea, PR China," Ocean and Coastal Management, vol. 49, no. 9-10, pp. 706-716, 2006.

[16] B. Wang, "New characteristics of environmental pollution in Bohai Sea in the 21 century," Ocean Development and Management, vol. 24, no. 3, pp. 117-119, 2007 (Chinese).

[17] X. Zhan, J. Sui, Y. Zhang, J. Ma, J. Wang, and L. Xue, "Status of marine environmental quality in China seas in 2001," Marine Environmental Science, vol. 21, no. 2, pp. 47-49, 2002 (Chinese).

[18] G. Wei, D. Tang, and S. Wang, "Distribution of chlorophyll and harmful algal blooms (HABs): a review on space based studies in the coastal environments of Chinese marginal seas," Advances in Space Research, vol. 41, no. 1, pp. 12-19, 2008.

[19] D. Z. Zhao, L. Zhao, F. S. Zhang, and X. Y. Zhang, “Temporal and spatial distributions and hazard degree of harmful algae blooms in China's coastal waters," Journal of Human and Ecological Risk Assessment, vol. 10, pp. 945-958, 2004.

[20] J. Wang and J. Wu, "Occurrence and potential risks of harmful algal blooms in the East China Sea," Science of the Total Environment, vol. 407, no. 13, pp. 4012-4021, 2009.

[21] D. Li and D. Daler, "Ocean pollution from land-based sources: East China Sea, China," Ambio, vol. 33, no. 1-2, pp. 107-113, 2004.

[22] J. Li, J. Huang, and J. Cheng, "Time and spatial distribution character of fertilizer consumption and potential pollution in China," Ecology and Environment, vol. 2, no. 2, pp. 145-149, 2003 (Chinese).

[23] J. Williams, "Understanding the overuse of chemical fertilizer in China: a synthesis of historic trends, recent studies, and field experiences," 2005, http://forestry.msu.edu/china/ new\%20folder/jo_fertilizer.pdf.

[24] W. Zhang, Y. Ji, J. Ma, Y. Wang, W. Ma, and F. Zhang, "Factors affecting fertilizer demand and supply in China," Resources Science, vol. 29, no. 6, pp. 162-169, 2007 (Chinese).

[25] S. Duan, F. Xu, and L. J. Wang, "Long-term changes in nutrient concentrations of the Changjiang River and principal tributaries," Biogeochemistry, vol. 85, no. 2, pp. 215-234, 2007. 

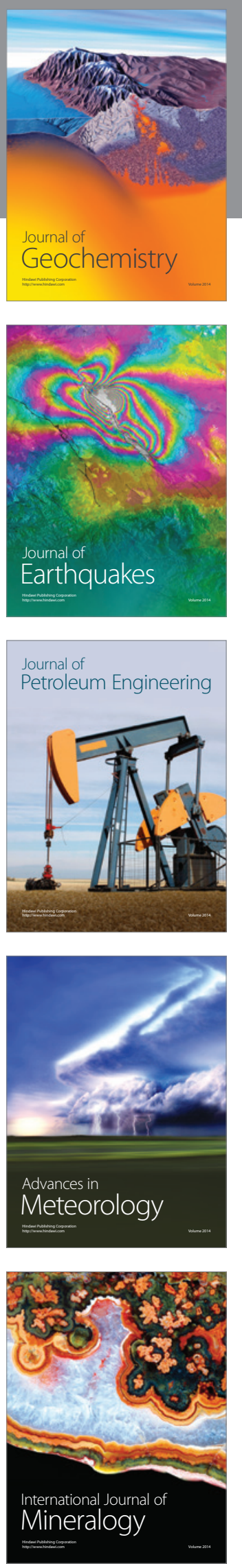
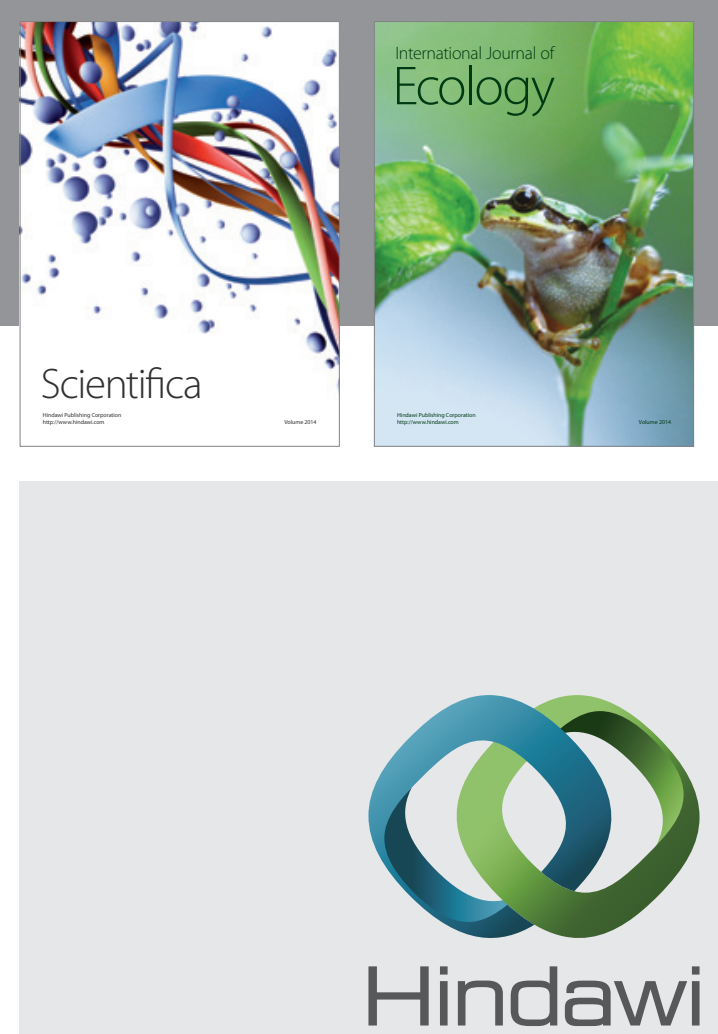

Submit your manuscripts at http://www.hindawi.com
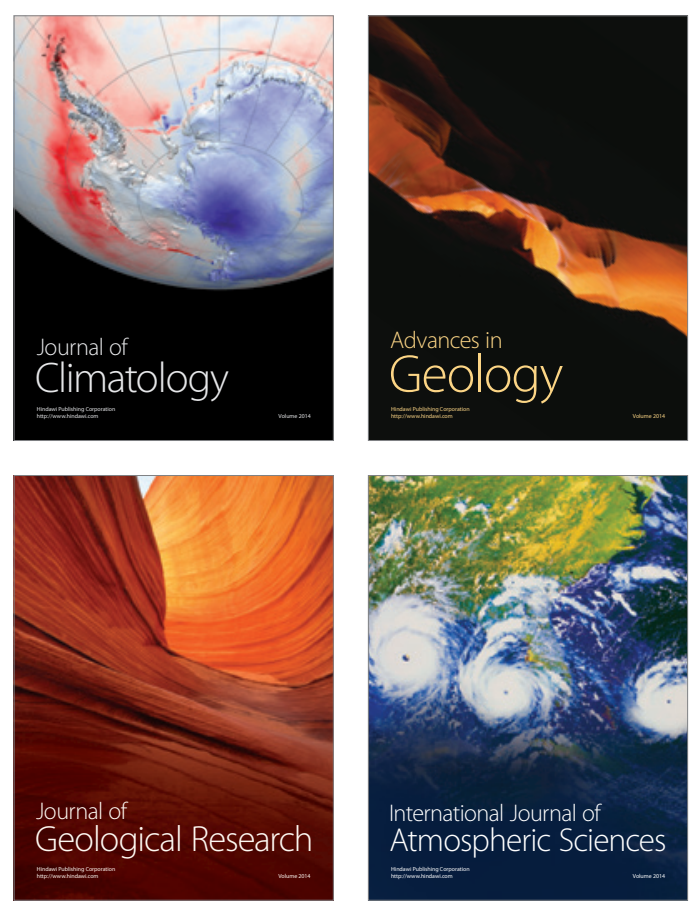
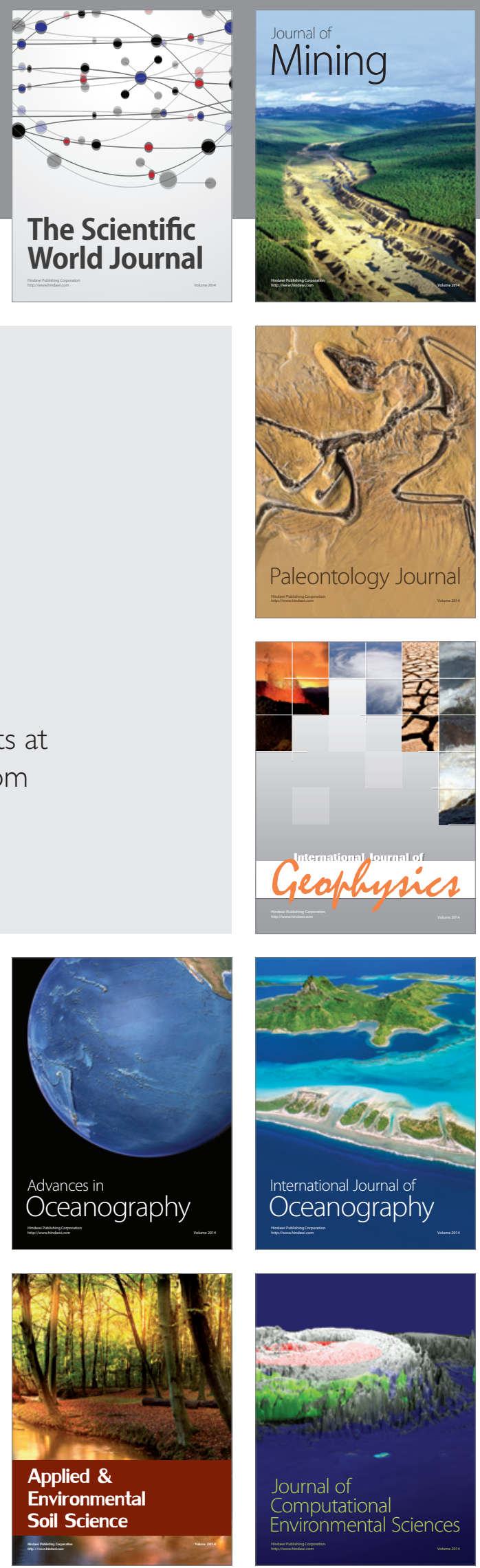